\title{
EFFECT OF THE ECOLOGICAL SYSTEM ON LETTUCE PRODUCTION GROWN UNDER DIFFERENT SOILLESS SYSTEMS
}

\author{
El-Sayed G. Khater*
}

\begin{abstract}
Soilless culture is a technique for crop production without soil. Crops are grown in the nutrient solution or on a proper medium, therefore, soilless culture involves no work such tools or machines. But it needs additional costs for growing systems and chemical fertilizers. It offers earlier growth and higher yield. The main aim of this research is to study the effect of aeration on preventing the root problems by comparing the hydroponic system with aeration to the aeroponic system. The obtained results indicated that the nitrogen, phosphorus, potassium, calcium and magnesium consumption rate ranged from 22.10 to $32.63,26.30$ to 34.65 , 85.80 to $120.30,14.88$ to 18.37 and 11.34 to $13.64 \mathrm{mg}^{p^{2} a n t^{-1}}$ day $^{-1}$, respectively, in hydroponic system and ranged from 25.65 to 37.35, 25.51 to $38.33,115.70$ to $127.50,17.15$ to 20.83 and10.94 to $14.90 \mathrm{mg}^{\text {plant }^{-1}}$ day $^{-1}$, respectively, after 50 days from transplanting in aeroponic system. The root length increased from 17.17 to $19.13 \mathrm{~cm}$ with increasing flow rate from 1.0 to $2.0 \mathrm{~L} \mathrm{~h}^{-1}$ in hydroponic system and increased from 17.45 to $19.56 \mathrm{~cm}$ with increasing flow rate from 0.5 to $1.5 \mathrm{~L} \mathrm{~h}^{-1}$ in aeroponic system. The fresh and dry mass of shoot and root were increased in aeroponic system better than those of hydroponic system. The total nutrients uptake values were higher in aeroponic system than those in hydroponic system. The average nitrogen, phosphorus, potassium, calcium and magnesium uptakes were 3.29, 1.25, 2.46, 0.43 and 0.44 \%and 2.13, 0.82, 1.81, 0.32 and $0.40 \%$ for aeroponic and hydroponic system, respectively. The average nitrate content was 155.52 and 113.73 mg plant ${ }^{-1}$ for aeroponic and hydroponic system, respectively.
\end{abstract}

Keywords: Aeroponics - Hydroponics - Lettuce - Nutrients consumption - Root length

* Lecturer. of Agric. Eng., Fac. of Agric., Benha Univ., Egypt. E-mail address: alsayed.khater@fagr.bu.edu.eg 


\section{INTRODUCTION}

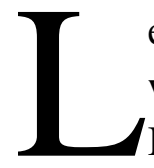

ettuce (Lactuca sativa L.) belongs to the family Compositae which is one of the most important vegetable crops in the world. It is cultivated mainly in open fields as well as under greenhouse conditions. Simple hydroponics like trough culture and aggregate system are much used in growing lettuce (Peiris and Weerakkody, 2015).

In horticultural crop production, the definition soilless cultivation encompasses all the systems that provide plant management in soilless conditions in which the supply of water and of minerals is carried out by nutrient solution, with or without a growing medium (e.g. rockwool, peat, perlite, pumice, coconut fiber, etc.). Soilless cultivation systems can be divided into: i) systems in the solid medium, using a substrate to support the plants, ii) systems in the liquid medium, which do not have other media for the support of plant roots and iii) systems in the aerated medium, the roots of the plants are suspended in a closed chamber and a nutrient solution is sprayed from below (Winsor and Schwarz, 1990). Hydroponic system is a method of growing plants using a mineral nutrient solution in water, without soil. In traditional agricultural methods soil is used as the medium whereby nutrients are dissolved in water, which can then be taken up by the plant roots, although the soil itself is not necessary. If nutrients are added to the water in which the plants are grown, then the soil medium is not needed. The ability to grow plants in areas where soil is not conducive for in-ground agriculture is the great advantage of hydroponics. Also, it is much more efficient in its water use as water stays in the system and can be reused, as opposed to it percolating through the soil and ultimately replenishing the groundwater reserves. Having greater control over nutrient levels results in healthier crops, fertilizers which often contribute to pollution are not used, pesticides are not needed to deal with pests, and ultimately, much higher and more stable crop yields are achieved (Johanson, 2009). Hydroponics has been primarily used for crop production under controlled conditions by supplying balanced nutrients in solution (Rana et al., 2011).

Aeroponic culture is an optional device of the soilless culture methods in growth controlled environments such as greenhouse. This method consists of enclosing the root system in a dark chamber and supplying a solution 
of water and mineral nutrients with a mist device. This technique has been applied successfully for the production of different horticultural species including lettuce (Cho et al., 1996; Gysi and von Allmen, 1997; He and Lee, 1998).

Unlike hydroponic, aeroponic did not use water as growing medium. In hydroponic, plant's roots are submerged into water to get water and nutrient to support its life. But for aeroponic, the nutrient is supply through mist spray by sprinkles or nozzles to plant's roots. An aeroponic farm system can set up with a few main components like a pump, nozzles, and growing chamber. There are a few types of aeroponic currently exist like low pressure type, high pressure type and commercial system. Different type of aeroponic required different kind of component to set up but the working concept is about the same (QI, 2012).

Benefit of aeroponics system is that of easy monitoring of nutrients and $\mathrm{pH}$. Aeroponics system provides precise plant nutrient requirements for the crop, thereby, reducing fertilizer requirement and minimizing risk of excessive fertilizer residues moving into the subterranean water table (Nichols, 2005). Aeroponics system also allows the measurement of nutrient uptake over time under varying conditions.

Lettuce is one of the best crops for soilless systems because it can be produced in a short period and, as a consequence, pest pressure is relatively low. Unlike tomato and cucumber, a high proportion of the harvested biomass is edible. With lettuce, income per unit area per unit time is very high. Other fast growing and high income generating crops are herbs such as basil and chive, which are being grown commercially in soilless systems (Rackocy and Hargreaves, 1993).

The most severe problem in the hydroponic system is the root rot which is due to the low oxygen level in the nutrient solution, therefore, proper aeration is required to overcome this propel. Aeroponic system is the proper solution to provide the plant with the required oxygen and nutrients, so that the main aim of this work is to study the effect of aeration on preventing the root problems by comparing the hydroponic system with aeration to the aeroponic system. 


\section{MATERIALA AND METHODS}

The experiment was carried out at Agricultural and Bio-Systems Engineering Department, Faculty of Agriculture Moshtohor, Benha University, Egypt (latitude $30^{\circ} 21^{`} \mathrm{~N}$ and $31^{\circ} 13^{`} \mathrm{E}$ ). During the period of February and March, 2015 season.

\subsection{System description:}

Fig. 1 illustrates the experimental setup. It shows hydroponic system, aeroponic system, solution tank and pumps.

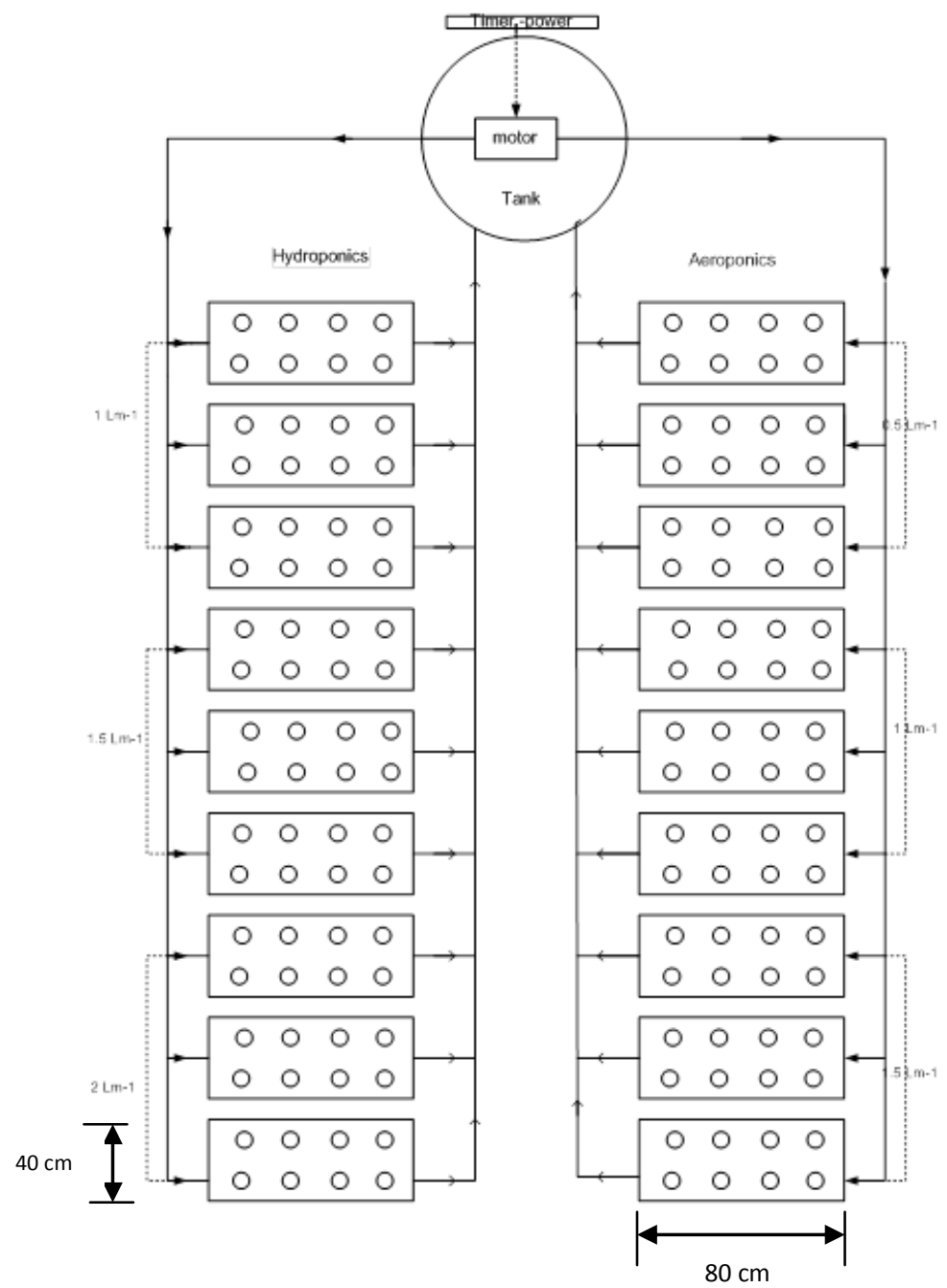

Fig. 1. The experimental setup 
The hydroponic system consists of nine rectangular polyethylene tanks used for lettuce plants culture. Dimensions of each tank are $80 \mathrm{~cm}$ long, $40 \mathrm{~m}$ wide and $30 \mathrm{~cm}$ high. The slope of hydroponic tanks was $2 \%$ and stand one $\mathrm{m}$ high above the ground. The hydroponic tanks were covered with foam boards to support the plants. Each hydroponic tank equipped with $15 \mathrm{~W}$ air blower of flow rate $850 \mathrm{~L} \mathrm{~h}^{-1}$ at $1.5 \mathrm{~m}$ head to increase dissolved oxygen concentrations. The solution was circulated by a $0.5 \mathrm{hp}$ pump in a closed system of flow rate $30 \mathrm{~L} \mathrm{~min}^{-1}$ at $25 \mathrm{~m}$ head from the solution tank to the upper ends of the hydroponic tanks through a $16 \mathrm{~mm}$ tube to supply each tank from the bottom of each tank to the solution tank.

Nine aeroponic tanks were located in the same greenhouse of a dimensions of each tank are $80 \mathrm{~cm}$ long, $40 \mathrm{~m}$ wide and $50 \mathrm{~cm}$ high. The aeroponic tanks were established $1 \mathrm{~m}$ above the ground. The aeroponic tanks covered with foam boards to support the plants. Each aeroponic tank provided by two fog nozzles located at the bottom of the tank for spraying nutrient solution inside the tank in order to keep the plant roots wet. The aeroponic tanks were divided to three groups, the first group was provided of two fog nozzles $\left(2 \mathrm{~L} \mathrm{~h}^{-1}\right.$ discharge), the second group was provided of two fog nozzles ( $4 \mathrm{~L} \mathrm{~h}^{-1}$ discharge) and the third group was provided of two fog nozzles $\left(6 \mathrm{~L} \mathrm{~h}^{-1}\right.$ discharge $)$. Small tubes $(16 \mathrm{~mm})$ were used to supply each aeroponic tank with solution discharged of the solution tank in a closed system.

The circular polyethylene tank of the nutrient solution system 500 liter capacity was used for collecting of drained solution by gravity from the ends of the hydroponic and aeroponic tanks. The amount of chemicals used in the system as described by Hoagland and Arnon (1950). Also a complete replacement for the nutrient solution was done every ten days.

\subsection{Lettuce plants:}

Lettuce seedlings were sown in the plastic cups $(7 \mathrm{~cm}$ diameter and $7 \mathrm{~cm}$ height) filled with peatmoss. The cups were irrigated daily using water with Hoagland and Arnon. Two weeks old lettuce seedlings were planted in the experimental tanks. The plant spacing on the row was $20 \mathrm{~cm}$ Khater (2006). 


\subsection{Treatment:}

The treatments were arranged in randomize complete block design in three replications. Two type of soilless culture (Hydroponic system and Aeroponic system). For hydroponic system three water flow rates 1.0, 1.5 and $2.0 \mathrm{~L} \mathrm{plant}^{-1} \mathrm{~h}^{-1}$ were considered intermittent flow 15 minute 'on' and 15 minute 'off'. For aeroponic system three water flow rates for aeroponic 0.5, 1.0 and $1.5 \mathrm{~L} \mathrm{plant}^{-1} \mathrm{~h}^{-1}$ were considered intermittent flow 15 minute 'on' and 15 minute 'off'.

\subsection{Measurements:}

Water samples were taken, at inlet and outlet of the hydroponic and aeroponic units for measuring Nitrogen $(\mathrm{N})$, Phosphorus (P), Potassium $(\mathrm{K})$, Calcium $(\mathrm{Ca})$ and Magnesium $(\mathrm{Mg})$ were measured every ten days during the experimental period. Root length was measured every ten days. The fresh and dry mass were measured at the end of the experiment. After measured fresh mass the plants were oven dried at $70{ }^{\circ} \mathrm{C}$ until constant weight was reached. Total content of macro elements were evaluated after being digested according to Chapman and Partt (1961). Nitrogen was determined by Kjeldahl digestion apparatus (Bremmer and Mulvaney, 1982). Potassium, Calcium and magnesium were determined by Photofatometer (Model Jenway PFP7 - Range 0 - 160 mmol L ${ }^{-1}$, USA) and phosphorus (P) was determined colorimetrically following the Murphy and Riley (1962) method. The nitrate was evaluated after being digested and measured by using salsalic acid as described by Chapman and Partt (1961).

\subsection{Statistical analysis:}

The statistical analysis for the data obtained was done according to Snedecor and Cochran (1980) and the treatments were compared using Least Significant Differences (LSD) test at 95\% confidence level (Gomez, 1984).

\section{RESULTS AND DISCUSSION \\ 3.1. Nutrients consumption rate: \\ Nitrogen, phosphorus, potassium, calcium and magnesium consumption rates were determined during the growth period of lettuce at different soilless culture systems and different flow rate. Any removal of nutrients}


from the solution can be equated with uptake by plants, provided that the system does not leak, and free from algae regardless of precipitation.

Fig. 2 show the nitrogen $(\mathrm{N})$, phosphorus $(\mathrm{P})$, potassium $(\mathrm{K})$, calcium (Ca) and magnesium $(\mathrm{Mg})$ consumption rate by lettuce plants during the growing period. The results indicate that the nutrients consumption rate was increased in aeroponic system better than those of hydroponic system. It could be seen that the $\mathrm{N}, \mathrm{P}, \mathrm{K}, \mathrm{Ca}$ and $\mathrm{Mg}$ consumption rate ranged from 22.10 to $32.63,26.30$ to $34.65,85.80$ to $120.30,14.88$ to 18.37 and 11.34 to $13.64 \mathrm{mg}$ plant $^{-1}$ day $^{-1}$, respectively, after 50 days from transplanting in hydroponic system and ranged from 25.65 to $37.35,25.51$ to $38.33,115.70$ to $127.50,17.15$ to 20.83 and 10.94 to $14.90 \mathrm{mg}$ plant $^{-1}$ day $^{-1}$, respectively, after 50 days from transplanting in aeroponic system.

The results also indicate that the nitrogen consumption rate was 18.86, 23.00 and $15.84 \mathrm{mg}$ plant $^{-1}$ day $^{-1}$ for $1.0,1.5$ and $2.0 \mathrm{~L} \mathrm{~h}^{-1}$ plant $^{-1}$ flow rate, respectively, at hydroponic system. On the other hand, the nitrogen consumption rate was $22.84,18.37$ and $15.39 \mathrm{mg} \mathrm{plant}^{-1} \mathrm{day}^{-1}$ for $0.5,1.0$ and $1.5 \mathrm{~L} \mathrm{~h}^{-1}$ plant $^{-1}$ flow rate, respectively, at aeroponic system.

The phosphorus consumption rate was $16.83,21.12$ and $13.78 \mathrm{mg} \mathrm{plant}^{-1}$ day $^{-1}$ for $1.0,1.5$ and $2.0 \mathrm{~L} \mathrm{~h}^{-1}$ plant $^{-1}$ flow rate, respectively, at hydroponic system. On the other hand, the phosphorus consumption rate was 24.13, 20.00 and $13.47 \mathrm{mg} \mathrm{plant}^{-1}$ day $^{-1}$ for $0.5,1.0$ and $1.5 \mathrm{~L} \mathrm{~h}^{-1}$ plant $^{-1}$ flow rate, respectively, at aeroponic system.

The potassium consumption rate was $66.60,78.88$ and $50.10 \mathrm{mg}$ plant $^{-1}$ day $^{-1}$ for $1.0,1.5$ and $2.0 \mathrm{~L} \mathrm{~h}^{-1}$ plant $^{-1}$ flow rate, respectively, at hydroponic system. On the other hand, the potassium consumption rate was 88.74, 79.48 and $64.62 \mathrm{mg}_{\text {plant }}{ }^{-1} \mathrm{day}^{-1}$ for $0.5,1.0$ and $1.5 \mathrm{~L} \mathrm{~h}^{-1}$ plant $^{-1}$ flow rate, respectively, at aeroponic system.

The calcium consumption rate was 9.61, 11.67 and $9.12 \mathrm{mg}$ plant $^{-1}$ day $^{-1}$ for $1.0,1.5$ and $2.0 \mathrm{~L} \mathrm{~h}^{-1}$ plant $^{-1}$ flow rate, respectively, at hydroponic system. On the other hand, the calcium consumption rate was 11.97, 10.83 and $9.56 \mathrm{mg}$ plant $^{-1}$ day $^{-1}$ for $0.5,1.0$ and $1.5 \mathrm{~L} \mathrm{~h}^{-1}$ plant $^{-1}$ flow rate, respectively, at aeroponic system. 


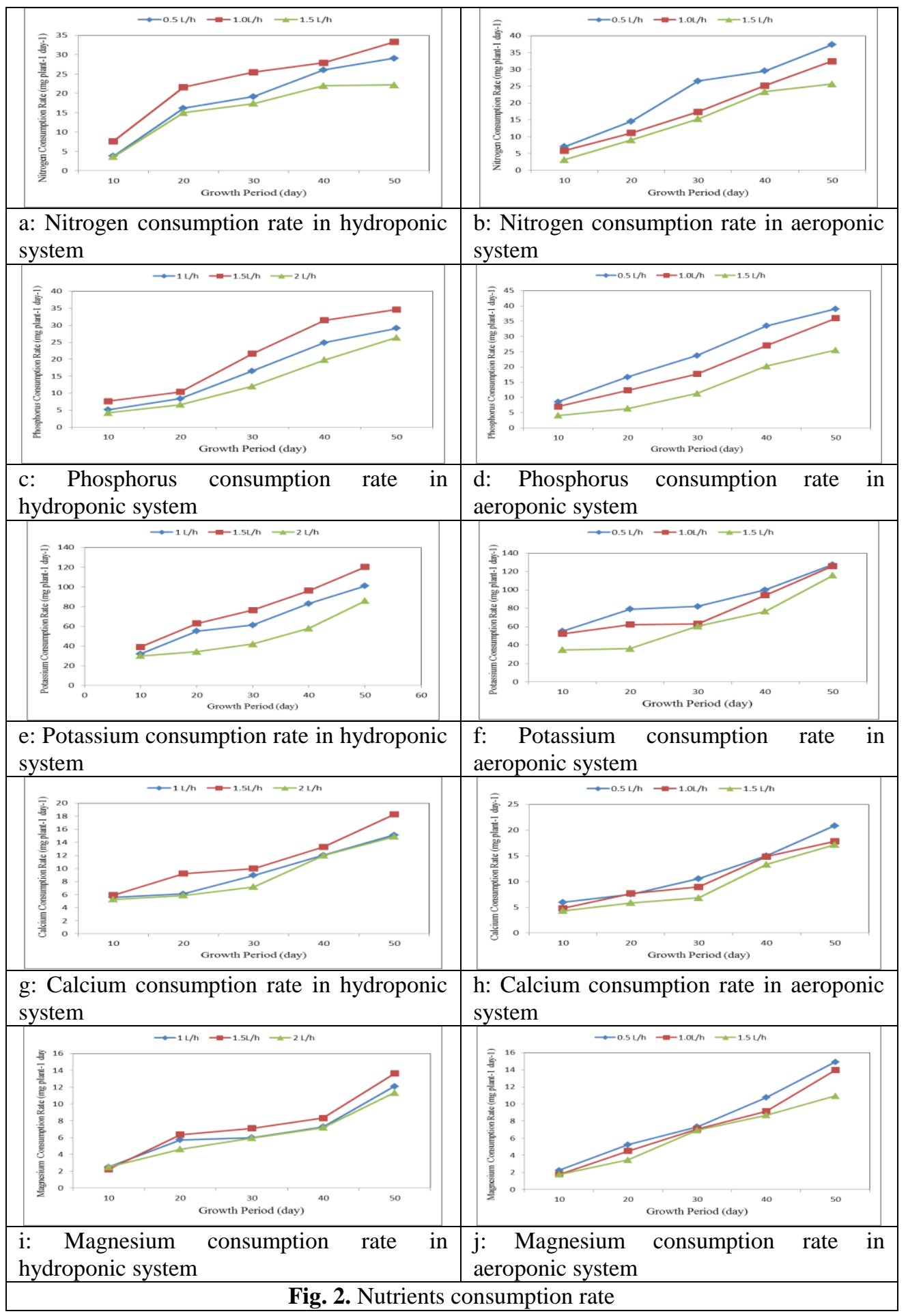


The results also indicate that the magnesium consumption rate was 6.76 , 7.55 and $6.45 \mathrm{mg}$ plant $^{-1}$ day $^{-1}$ for 1.0, 1.5 and $2.0 \mathrm{~L} \mathrm{~h}^{-1}$ plant ${ }^{-1}$ flow rate, respectively, at hydroponic system. On the other hand, the magnesium consumption rate was $11.97,10.83$ and $9.56 \mathrm{mg} \mathrm{plant}^{-1}$ day $^{-1}$ for $0.5,1.0$ and $1.5 \mathrm{~L} \mathrm{~h}^{-1}$ plant $^{-1}$ flow rate, respectively, at aeroponic system.

The highest value of $\mathrm{N}, \mathrm{P}, \mathrm{K}, \mathrm{Ca}$ and $\mathrm{Mg}$ consumption rate (32.63, 34.65, 120.30, 18.37 and $13.64 \mathrm{mg}$ plant $^{-1}$ day $^{-1}$, respectively) was obtained with a flow rate of $1.5 \mathrm{~L} \mathrm{~h}^{-1}$ plant $^{-1}$ at hydroponic system. These results agreed with those obtained by Khater (2006) and Genuncio (2012). While, the N, $\mathrm{P}, \mathrm{K}, \mathrm{Ca}$ and $\mathrm{Mg}$ consumption rate decreases with increasing flow rate in aeroponic system. It could be seen that when the flow rate increased from 0.5 to $1.5 \mathrm{~L} \mathrm{~h}^{-1}$ plant $^{-1}$, the $\mathrm{N}, \mathrm{P}, \mathrm{K}, \mathrm{Ca}$ and $\mathrm{Mg}$ consumption rate significantly decreased from 37.35 to $25.65,38.33$ to $25.51,88.74$ to 64.62, 14.90 to 10.94 and 8.09 to $6.37 \mathrm{mg}$ plant $^{-1}$ day $^{-1}$, respectively. Decreasing nutrients consumption rate with increasing the flow rate in aeroponic system may be due to a higher flow rates, it causes high stress on the roots causing root crushing which in turn decrease the nutrients consumption.

\subsection{Root length:}

Figs. $3 \mathrm{a}$ and $\mathrm{b}$ show the root length of lettuce plants grown in hydroponic and aeroponic systems at different flow rates. The results indicate that the root length was increased in aeroponic system taller than those of hydroponic system. It could be seen that the root length increased from 17.17 to $19.13 \mathrm{~cm}$ after 50 days from transplanting in hydroponic system and increased from 17.45 to $19.56 \mathrm{~cm}$ after 50 days from transplanting in aeroponic system. These results agreed with those obtained by Hale et al. (2015) whose found that the aeroponics produced fastest growth rates.

Also, the results indicate that the root length increases with increasing flow rate and plant age. It could be seen that when the flow rate increased from 1.0 to $2.0 \mathrm{~L} \mathrm{~h}^{-1}$ plant $^{-1}$ in hydroponic system, the length of root significantly increased from 3.35 to $3.40 \mathrm{~cm}(1.47 \%)$ and 17.17 to 19.13 $\mathrm{cm}(10.25 \%)$ after 10 and 50 days, respectively, from transplanting. It also indicate that when the time after transplanting increased from 10 to 
50 days, the length of root significantly increase from 3.35 to $17.17,3.18$ to 18.27 and 3.40 to $19.13 \mathrm{~cm}$ at $1.0,1.5$ and $2.0 \mathrm{~L} \mathrm{~h}^{-1}$ flow rate, respectively. On the other hand, the results indicated that when the flow rate increased from 0.5 to $1.5 \mathrm{~L} \mathrm{~h}^{-1}$ plant ${ }^{-1}$ in aeroponic system, the length of root significantly increased from 3.31 to $3.75 \mathrm{~cm}(11.73 \%)$ and 17.45 to $19.56 \mathrm{~cm}(10.79 \%)$ after 10 and 50 days, respectively, from transplanting. It also indicate that when the time after transplanting increased from 10 to 50 days, the length of root significantly increase from 3.31 to $17.45,3.47$ to 19.17 and 3.75 to $19.56 \mathrm{~cm}$ at $0.5,1.0$ and 1.5 $\mathrm{L} \mathrm{h}^{-1}$ flow rate, respectively. These results agreed with those obtained by Khater (2006) and Khater et al. (2015) whose found that the length of root was increased with increasing the flow rate.

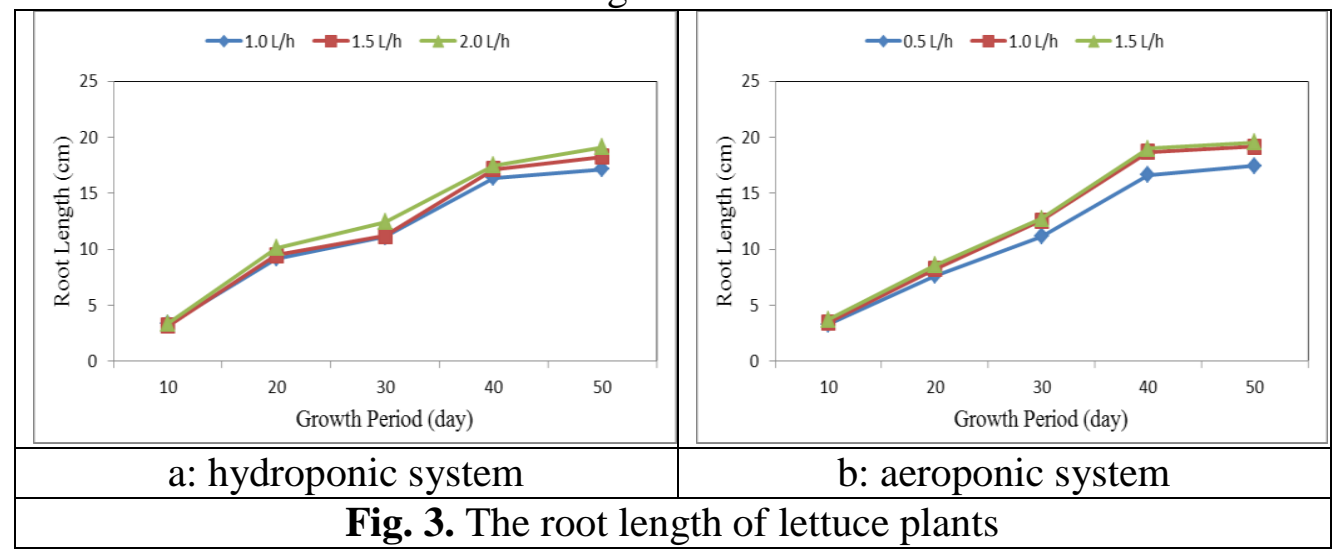

Multiple regression analysis was carried out to obtain a relationship between the root length (RL, cm) of lettuce plants at age from 1-50 days at different flow rates. The best form was as follows:

$$
\begin{array}{lll}
\mathrm{RL}=83.136-1.727 \mathrm{~T}+1.072 \mathrm{Q} & \mathrm{R}^{2}=0.841 & \text { for hydroponicsystetem } \\
\mathrm{RL}=-1.475+0.404 \mathrm{~T}+1.492 \mathrm{Q} & \mathrm{R}^{2}=0.952 & \text { for aeroponic systetem } \\
\text { Where:- } & &
\end{array}
$$$$
\mathrm{RL} \text { is the root length, } \mathrm{cm}
$$

\subsection{Fresh and dry mass:}

\subsubsection{Fresh and dry mass of shoot:}

Figs. $4 \mathrm{a}$ and $\mathrm{b}$ show the fresh and dry mass of shoot production of lettuce plants grown in hydroponic and aeroponic systems at different flow rates 
at the end of growing period (50 days). The results indicate that the fresh and dry mass of shoot were increased in aeroponic system over those of hydroponic system. It could be seen that the highest values of fresh and dry mass of shoot (290.84 and $39.41 \mathrm{~g} \mathrm{plant}^{-1}$ ) were found with aeroponic system, while, the lowest values of fresh and dry mass (134.28 and 17.52 $\mathrm{g} \mathrm{plant}^{-1}$ ) were found with hydroponic system. The fresh and dry mass of shoot for lettuce plants grown aeroponic system were 2.17 and 2.25 times more than those grown in hydroponic system, respectively. These results agreed with those obtained by Martin-Laurent et al. (1997) whose found that the Plants grown aeroponically were twice as high as those in hydroponics.

The results also indicate that the fresh and dry mass of shoot were 143.25, 222.41 and 134.28 g plant $^{-1}$ and 19.87, 23.41 and 17.52 g plant $^{-1}$ for 1.0, 1.5 and $2.0 \mathrm{~L} \mathrm{~h}^{-1}$ plant $^{-1}$ flow rate, respectively, at hydroponic system. On the other hand, the fresh and dry mass of shoot were 290.84, 227.13 and 260.76 g plant $^{-1}$ and 39.41, 38.51 and 36.15 g plant $^{-1}$ for $0.5,1.0$ and $1.5 \mathrm{~L}$ $\mathrm{h}^{-1}$ plant $^{-1}$ flow rate, respectively, at aeroponic system. The statistical analysis showed that the interaction between both flow rate and plant age was significant.

The highest values of fresh and dry mass (222.41 and $23.41 \mathrm{~g} \mathrm{plant}^{-1}$ ) were obtained with a flow rate of $1.5 \mathrm{~L} \mathrm{~h}^{-1}$ plant $^{-1}$ at hydroponic system. These results agreed with those obtained by Khater (2006) and Genuncio (2012) whose found that the highest values of fresh and dry mass were found with a flow rate of $1.5 \mathrm{~L} \mathrm{~h}^{-1}$ plant $^{-1}$. While, the fresh and dry mass decreases with increasing flow rate in aeroponic system. It could be seen that when the flow rate increased from 0.5 to $1.5 \mathrm{~L} \mathrm{~h}^{-1}$ plant $^{-1}$, the fresh and dry mass significantly decreased from 290.84 to $260.76 \mathrm{~g} \mathrm{plant}^{-1}$ (10.34\%) and 39.41 to 36.15 g plant $^{-1}(8.27 \%)$. Decreasing fresh and dry mass with increasing the flow rate in aeroponic system may be due to a higher flow rates, it causes high stress on the roots causing root crushing which in turn decrease the nutrients consumption. Fresh mass of lettuce plant ranged from 134.28 to $290.84 \mathrm{~g} \mathrm{plant}^{-1}$ depending treatments under study compared to 119 to $298 \mathrm{~g}$ plant $^{-1}$ for the traditional cultivation (Joseph et al., 2015). 


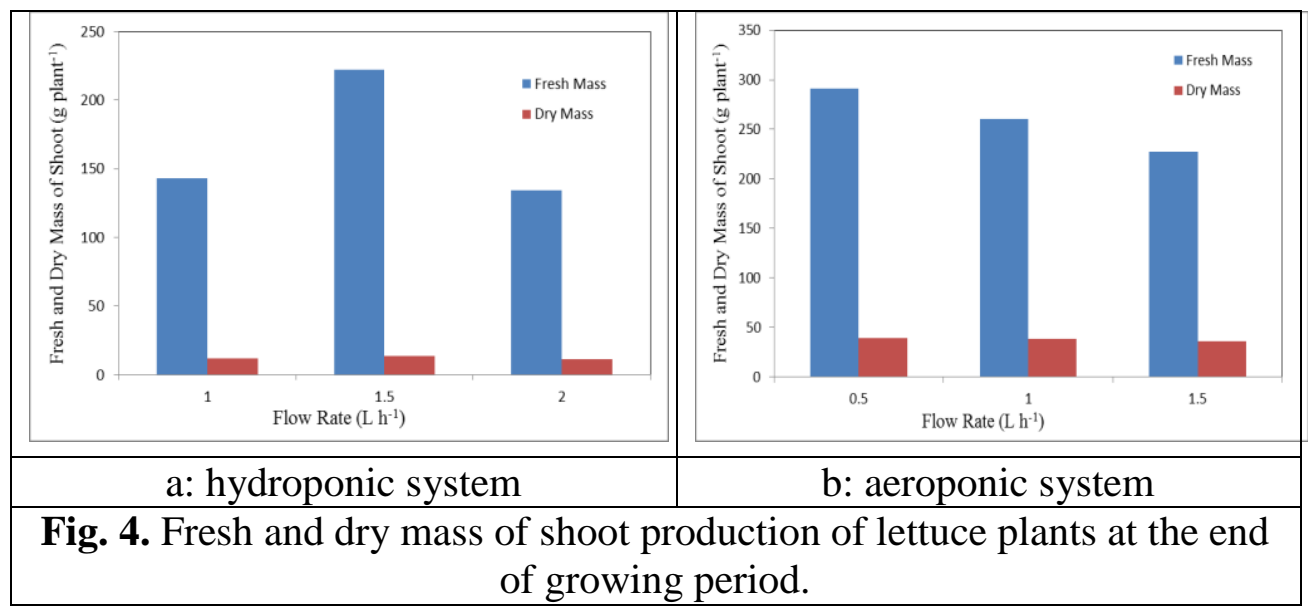

\subsubsection{Fresh and dry mass of root:}

Figs. $5 \mathrm{a}$ and $\mathrm{b}$ show the fresh and dry mass of root production of lettuce plants grown in hydroponic and aeroponic systems at different flow rates at the end of growing period (50 days). The results indicate that the fresh and dry mass of root were increased in aeroponic system over those of hydroponic system. It could be seen that the highest values of fresh and dry mass of root (96.38 and $11.87 \mathrm{~g} \mathrm{plant}^{-1}$ ) were found with aeroponic system, while, the lowest values of fresh and dry mass of root (73.55 and $8.75 \mathrm{~g} \mathrm{plant}^{-1}$ ) were found with hydroponic system. These results agreed with those obtained by Martin-Laurent et al. (1997) whose found that the Plants grown aeroponically showed greater fresh and dry mass of root compared to the plants grown hydroponically.

The results also indicate that the fresh and dry mass of root were 75.63, 86.17 and $73.53 \mathrm{~g} \mathrm{plant}^{-1}$ and 9.22, 10.01 and $8.75 \mathrm{~g} \mathrm{plant}^{-1}$ for 1.0, 1.5 and $2.0 \mathrm{~L} \mathrm{~h}^{-1}$ plant $^{-1}$ flow rate, respectively, at hydroponic system. On the other hand, the fresh and dry mass of root were 96.38, 85.09 and $79.51 \mathrm{~g}$ plant $^{-1}$ and 11.87, 10.05 and 9.71 g plant $^{-1}$ for $0.5,1.0$ and $1.5 \mathrm{~L} \mathrm{~h}^{-1}$ plant $^{-1}$ flow rate, respectively, at aeroponic system. The statistical analysis showed that the interaction between both flow rate and plant age was significant.

In hydroponic system, the highest values of fresh and dry mass of root were 86.17 and $10.01 \mathrm{~g}$ plant ${ }^{-1}$ were obtained with a flow rate of $1.5 \mathrm{~L} \mathrm{~h}^{-1}$ plant $^{-1}$, while, the lowest values of fresh and dry mass of root were 73.55 
and $8.75 \mathrm{~g} \mathrm{plant}^{-1}$ were found with a flow rate $2.0 \mathrm{~L} \mathrm{~h}^{-1}$. On the other hand, in aeroponic system, the highest values of fresh and dry mass of root were 96.38 and $11.87 \mathrm{~g}$ plant $^{-1}$ were obtained with a flow rate of 0.5 $\mathrm{L} \mathrm{h}^{-1}$ plant $^{-1}$, while, the lowest values of fresh and dry mass of root were 79.51 and $9.71 \mathrm{~g}$ plant ${ }^{-1}$ were found with a flow rate $1.5 \mathrm{~L} \mathrm{~h}^{-1}$. Increasing fresh and dry mass of roots was concomitant with increasing the fresh and dry mass of shoots at hydroponic and aeroponic systems may be due to increasing in nutrient consumption rate.

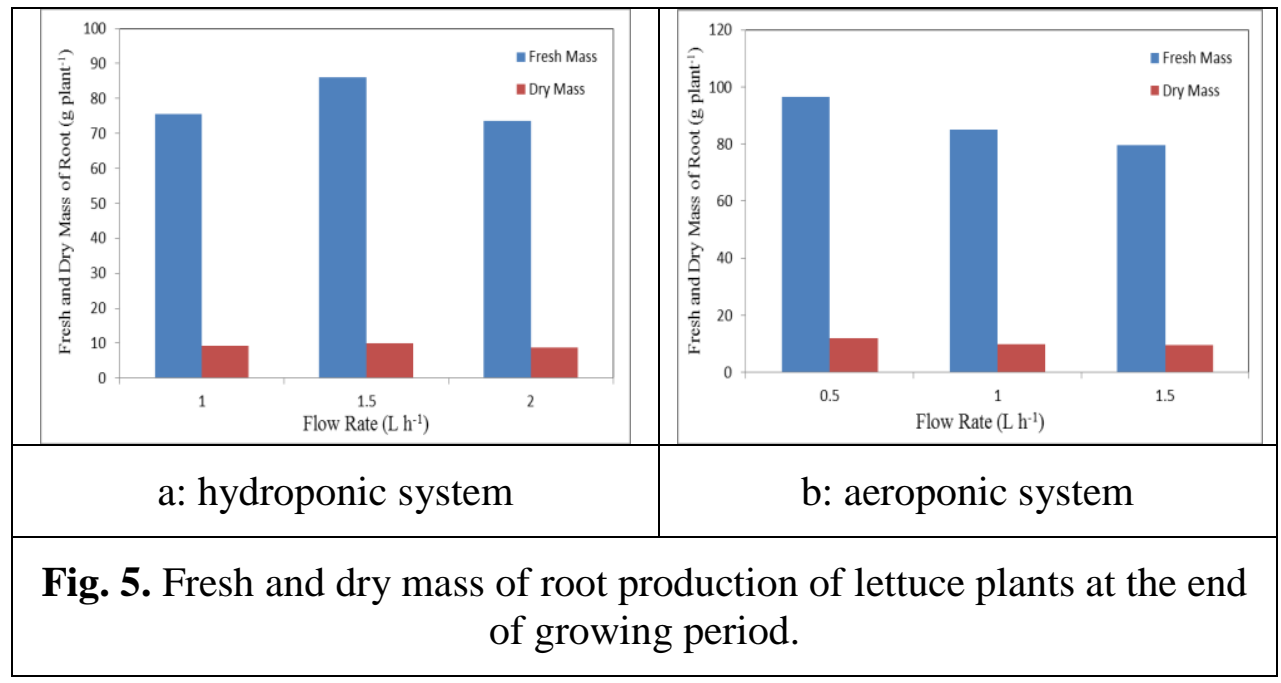

\subsection{Nutrients uptake:}

Fig. 6 shows the nitrogen $(\mathrm{N})$, phosphorus $(\mathrm{P})$, potassium $(\mathrm{K})$, calcium $(\mathrm{Ca})$ and magnesium $(\mathrm{Mg})$ uptake of lettuce plants grown in hydroponic and aeroponic systems at different flow rates at the end of growing period (50 days). The results indicate that the nutrients uptakes were increased in aeroponic system over those of hydroponic system. It could be seen that the $\mathrm{N}, \mathrm{P}, \mathrm{K}, \mathrm{Ca}$ and $\mathrm{Mg}$ uptakes were 3.29, 1.25, 2.46, 0.43 and $0.44 \%$, respectively, were found with aeroponic system, while, the $\mathrm{N}, \mathrm{P}, \mathrm{K}, \mathrm{Ca}$ and $\mathrm{Mg}$ uptakes were $2.13,0.82,1.81,0.32$ and $0.40 \%$, respectively, were found with hydroponic system.

The results also indicate that the nitrogen uptake was 1.96, 2.24 and 2.20 $\%$ for $1.0,1.5$ and $2.0 \mathrm{~L} \mathrm{~h}^{-1}$ plant $^{-1}$ flow rate, respectively, at hydroponic system. On the other hand, the nitrogen uptake was 3.41, 3.24 and $3.22 \%$ for $0.5,1.0$ and $1.5 \mathrm{~L} \mathrm{~h}^{-1}$ plant $^{-1}$ flow rate, respectively, at aeroponic system. 


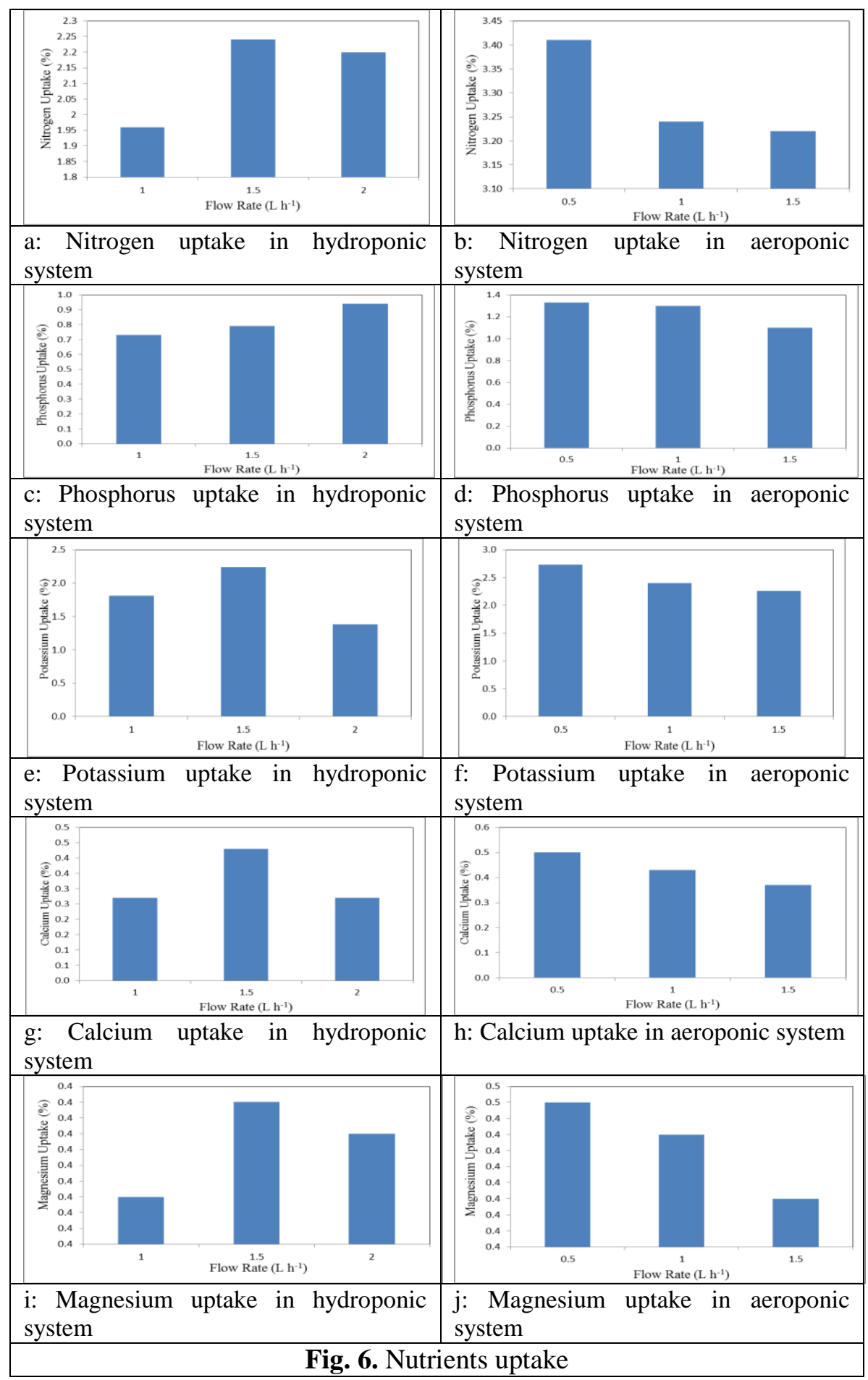


The results also indicate that the phosphorus uptake increases with increasing flow rate in hydroponic system. It could be seen that when the flow rate increased from 1.0 to $2.0 \mathrm{~L} \mathrm{~h}^{-1}$ plant $^{-1}$, the phosphorus uptake increased from 0.73 to $0.94 \%$. On the other hand, the phosphorus uptake decreases with increasing flow rate in aeroponic system. It could be seen that when the flow rate increased from 0.5 to $1.5 \mathrm{~L} \mathrm{~h}^{-1}$ plant ${ }^{-1}$, the phosphorus uptake decreased from 1.33 to $1.10 \%$.

The potassium uptake was 1.81, 2.24 and $1.38 \%$ for $1.0,1.5$ and $2.0 \mathrm{~L} \mathrm{~h}^{-1}$ plant $^{-1}$ flow rate, respectively, at hydroponic system. While, the potassium uptake was 2.73, 2.40 and $2.26 \%$ for $0.5,1.0$ and $1.5 \mathrm{~L} \mathrm{~h}^{-1}$ plant $^{-1}$ flow rate, respectively, at aeroponic system.

The calcium uptake was $0.27,0.43$ and $0.27 \%$ for $1.0,1.5$ and $2.0 \mathrm{~L} \mathrm{~h}^{-1}$ plant $^{-1}$ flow rate, respectively, at hydroponic system. While, the calcium uptake was $0.50,0.43$ and $0.37 \%$ for $0.5,1.0$ and $1.5 \mathrm{~L} \mathrm{~h}^{-1}$ plant $^{-1}$ flow rate, respectively, at aeroponic system.

The magnesium uptake was $0.38,0.41$ and $0.40 \%$ for $1.0,1.5$ and $2.0 \mathrm{~L}$ $\mathrm{h}^{-1}$ plant $^{-1}$ flow rate, respectively, at hydroponic system. On the other hand, the magnesium uptake was $0.45,0.44$ and $0.42 \%$ for $0.5,1.0$ and $1.5 \mathrm{~L} \mathrm{~h}^{-1}$ plant $^{-1}$ flow rate, respectively, at aeroponic system.

In hydroponic system, the highest values of the $\mathrm{N}, \mathrm{P}, \mathrm{K}, \mathrm{Ca}$ and $\mathrm{Mg}$ uptakes were $2.24,0.94,2.24,0.43$ and $0.41 \%$, respectively, were obtained with a flow rate of $1.5 \mathrm{~L} \mathrm{~h}^{-1}$ plant ${ }^{-1}$, while, in aeroponic system the highest values of the $\mathrm{N}, \mathrm{P}, \mathrm{K}, \mathrm{Ca}$ and $\mathrm{Mg}$ uptakes were 3.41, 1.33, $2.73,0.50$ and $0.45 \%$, respectively, were obtained with a flow rate of 0.5 $\mathrm{L} \mathrm{h}^{-1}$ plant $^{-1}$. Increasing the nutrients uptake by lettuce plant were concomitant with increasing fresh and dry mass of shoot with a flow rate of 1.5 and $0.5 \mathrm{~L} \mathrm{~h}^{-1}$ for hydroponic and aeroponic system, respectively, may be due to increasing in nutrient consumption rate. These results agreed with those obtained by Khater and Ali (2015).

\subsection{Nitrate content in plant:}

Figs. 7 a and $b$ show the nitrate $\left(\mathrm{NO}_{3}-\mathrm{N}\right)$ content by lettuce plants grown in hydroponic and aeroponic systems at different flow rates at the end of growing period (50 days). The results indicate that the nitrate content was 
increased in aeroponic system over those of hydroponic system. It could be seen that the average nitrate content was $155.52 \mathrm{mg}$ plant $^{-1}$ was found with aeroponic system, while, the average nitrate content was $113.73 \mathrm{mg}$ plant $^{-1}$ was found with hydroponic system.

The results also indicate that the nitrate content in lettuce plant was 112.05, 121.74 and $107.39 \mathrm{mg}_{\text {plant }}{ }^{-1}$ for $1.0,1.5$ and $2.0 \mathrm{~L} \mathrm{~h}^{-1}$ plant $^{-1}$ flow rate, respectively, at hydroponic system. While, the nitrate content in lettuce plant was $159.89,157.91$ and $148.76 \mathrm{mg} \mathrm{plant}^{-1}$ for $0.5,1.0$ and $1.5 \mathrm{~L} \mathrm{~h}^{-1}$ plant $^{-1}$ flow rate, respectively, at aeroponic system. The statistical analysis showed that the effect of flow rate on nitrate content was significant.

In hydroponic system, the highest values of nitrate content $(121.74 \mathrm{mg}$ plant $^{-1}$ ) were obtained with a flow rate of $1.5 \mathrm{~L} \mathrm{~h}^{-1}$ plant ${ }^{-1}$, while, in aeroponic system the highest values of nitrate content (159.89 mg plant $\left.{ }^{-1}\right)$ were obtained with a flow rate of $0.5 \mathrm{~L} \mathrm{~h}^{-1}$ plant ${ }^{-1}$. Increasing nitrate content in lettuce plant was concomitant with increasing nitrogen uptake with a flow rate of 1.5 and $0.5 \mathrm{~L} \mathrm{~h}^{-1}$ for hydroponic and aeroponic system, respectively, may be due to increasing in nutrient consumption rate. These results agreed with those obtained by Khater and Ali (2015).

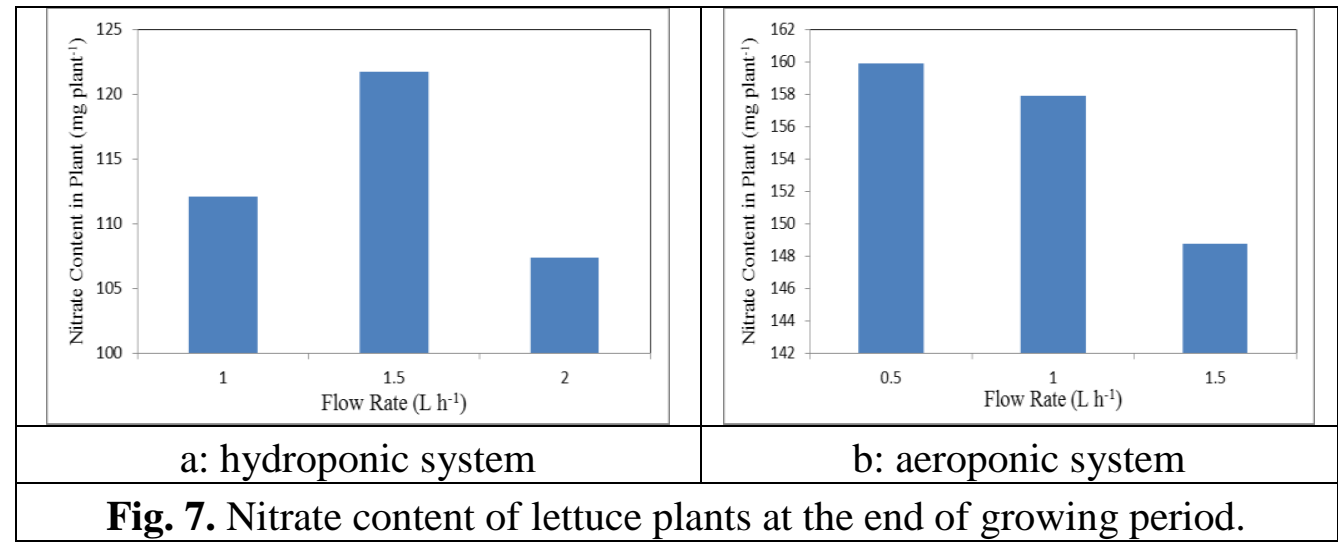

\section{CONCLUSIONS}

The experiment was carried out to study the effect of aeration on preventing the root problems by comparing the hydroponic system with aeration to the aeroponic system. The obtained results can be summarized as follows: 
- The N, P, K, Ca and $\mathrm{Mg}$ consumption rate ranged from 22.10 to $32.63,26.30$ to $34.65,85.80$ to $120.30,14.88$ to 18.37 and 11.34 to $13.64 \mathrm{mg} \mathrm{plant}^{-1}$ day $^{-1}$, respectively, after 50 days from transplanting in hydroponic system and ranged from 25.65 to $37.35,25.51$ to $38.33,115.70$ to $127.50,17.15$ to 20.83 and10.94 to $14.90 \mathrm{mg} \mathrm{plant}^{-1}$ day $^{-1}$, respectively, after 50 days from transplanting in aeroponic system.

- The root length increases with increasing flow rate, the root length increased from 17.17 to $19.13 \mathrm{~cm}$ after 50 days from transplanting with increasing flow rate from 1.0 to $2.0 \mathrm{~L} \mathrm{~h}^{-1}$ in hydroponic system and increased from 17.45 to $19.56 \mathrm{~cm}$ after 50 days from transplanting with increasing flow rate from 0.5 to $1.5 \mathrm{~L} \mathrm{~h}^{-1}$ in aeroponic system.

- The highest values of fresh and dry mass of shoot were 290.84 and $39.41 \mathrm{~g} \mathrm{plant}^{-1}$ were found with aeroponic system, while, the lowest values of fresh and dry mass were 134.28 and $17.52 \mathrm{~g}$ plant $^{-1}$ were found with hydroponic system.

- The highest values of fresh and dry mass of root were 96.38 and $11.87 \mathrm{~g} \mathrm{plant}^{-1}$ were found with aeroponic system, while, the lowest values of fresh and dry mass of root were 73.55 and $8.75 \mathrm{~g} \mathrm{plant}^{-1}$ were found with hydroponic system.

- The total nutrients uptake values were higher in aeroponic system than those in hydroponic system. The average nitrogen, phosphorus, potassium, calcium and magnesium uptakes were $3.29,1.25,2.73$, 0.50 and $0.44 \%$ and $2.13,0.82,2.24,0.43$ and $0.40 \%$ for aeroponic and hydroponic system, respectively.

- The average nitrate content in aeroponic system was $155.52 \mathrm{mg}$ plant $^{-}$ ${ }^{1}$, while, the average nitrate content in hydroponic system was 113.73 mg plant ${ }^{-1}$.

\section{REFERENCES}

Bremmer, J.M. and Mulvaney C.S., 1982. Nitrogen-total. In: Page, A.L., Miller, R.H., Keeney, D.R. (Eds.), Methods of Soil Analysis, 
Part 2. Chemical and Microbiological Properties, second ed., Agronomy series No. 9 ASA, SSSA, Madison, WI, pp. 595-624.

Chapman, H.D. and Partt, F.P., 1961. Methods of Analysis of Soils, Plant and Water. California University, pp. 150-200.

Cho, Y.D., Kang S.G., Kim Y.D., Shin G.H. and Kim K.T., 1996. Effect of culture systems on growth and yield of cherry tomatoes in hydroponics. RDA J. Agric. Sci. 38, 563-567.

Genuncio, G.C., Gomes M., Ferrari A.C., Majerowicz N. and Zonta E., 2012. Hydroponic lettuce production in different concentrations and flow rates of nutrient solution. Hort. Brasileira 30, 526-530.

Gomez, K.A., 1984. Statistical Procedures for Agricultural Research, 2nd ed. John Wiely \& Sons, New York, USA 680 pp.

Gysi, C., von Allmen F., 1997. Balance of water and nutrients in tomatoes grown on soilless systems. Agrarforschung 4:1.

Hale, C., Lamotte F. and Iannetta P., 2015. The development of hyroponic and aeroponic culture systems for the high-throughout production of basil. www.hutton.ac.uk/webfm_send/413

He, J. and Lee S.K., 1998. Growth and photosynthetic responses of three aeroponically grown lettuce cutivars (Latuca sativa L) to different root zone temperatures and growth irradiances under tropical aerial conditions, Journal of Horticultural Science 23, 173-180.

Hoagland, D.R. and Arnon D. I., 1950. The water culture method for growing plants without soil. Univ. of Calif., Agric. Exp. Sta. Cir. $347 \mathrm{pp}$.

Johanson, E.K., 2009. Aquaponics and Hydroponics on a Budget. Tech Directions 69 (2), 21-23.

Joseph, S.V., Bettiga C., Ramirez C. and Soto-Adames F.N., 2015. Evidence of protaphorura fimata (Collembola: Poduromorpha: Onychiuridae) feeding on germinating lettuce in the Salinas Valley of California. J. Econ. Entomol. 24, 1-9.

Khater, E.G., 2006. Aquaponics: the integration of fish and vegetable culture in recirculating systems. M.Sc. Thesis, in Agric. Eng., Fac. Agric., Moshtohor, Benha Univ., Egypt. 
Khater, E.G., Ali, S.A., 2015. Effect of flow rate and length of gully on lettuce plants in aquaponic and hydroponic systems. J. Aquacult. Res. Dev. 6: 3. http://dx.doi.org/10.4172/2155-9546.1000318.

Khater, E.G., Bahnasawy A.H., Shams A.S., Hassaan M.S. and Hassan Y.A., 2105. Utilization of effluent fish farms in tomato cultivation. Ecol. Eng. 83, 199 - 207.

Martin-Laurent, F., Lee S.K., Tham F.Y., He J., Diem H.G. and Durand P., 1997. A new approach to enhance growth and nodulation of Acacia mangium through aeroponic culture. Biol. Fertil. Soils 25, 7-12.

Murphy, J. and Riley J.P., 1962. A modified single solution method for determination of phosphate in natural waters. Anal. Chem. Acta 27, 31-36.

Nichols, M.A., 2005. Aeroponics and potatoes. Proceedings of the first international symposium on root and tuber crops 'Food Down Under'. Leiden. Netherlands. Int. Soc. Hort. Sci. (ISHS). pp. 201206.

Peiris P.U. and Weerakkody W.A., 2015. Effect of Organic Based Liquid Fertilizers on Growth Performance of Leaf Lettuce (Lactuca Sativa L.). International Conference on Agricultural, Ecological and Medical Sciences (AEMS-2015) April 7-8, 2015 Phuket (Thailand).

QI, L.J., 2012. Development of hydro-atomized spraying system for a controlled environment aeroponic farm. Fac. Electrical Engineering, University Teknikal Malaysia Melaka.

Rackocy, J.E. and Hargreaves J.A., 1993. Integration of vegetable hydroponics with fish culture: a review. In: Wang J.K., Ed. Techniques for Modern Aquaculture, American Society of Agricultural Engineering, St. Joseph, MI, 112-136.

Rana, S., Bag, S.K., Golder, D., Mukherjee (Roy), S., Pradhan, C. and Jana, B.B., 2011. Reclamation of municipal domestic wastewater by aquaponics of tomato plants. Ecol. Eng. 37, 981988.

Snedecor, G.W. and Cochran W.G. 1980. Statistical Methods, $7^{\text {th }}$ Ed., Iowa State University Press, Ames, Iowa, USA. 
Winsor, G. W. and Schwarz M., 1990. Soilless culture for horticulture crop production. FAO Plant Production and Protection Paper, Publication No. 101, Rome, Italy.

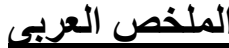

\section{تأثثير النظام البيئى على انتاج الخس النامى تحت نظم مختلفة بدون تربة}

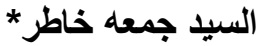

يهدف هذا البحث إلى در اسة تأثثير التهويـة للتغلب على مشـاكل الجذور من خـال المقارنة بين

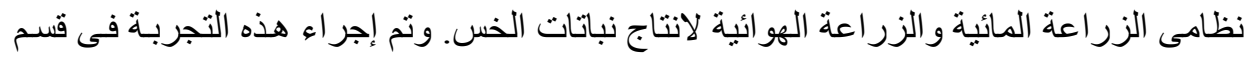

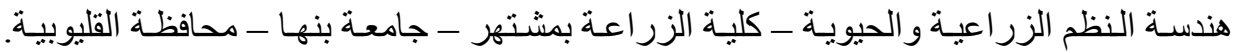

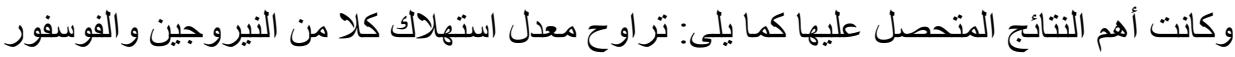

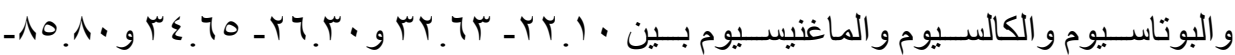

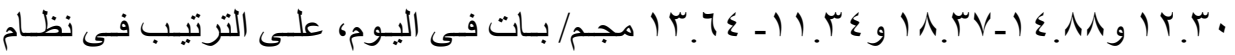

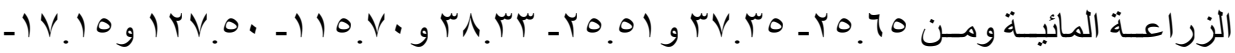

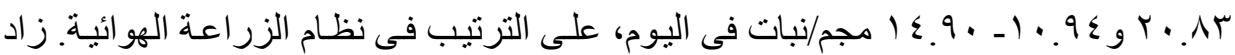

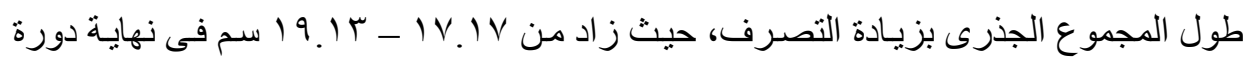

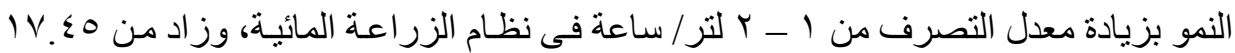

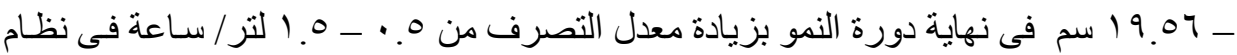

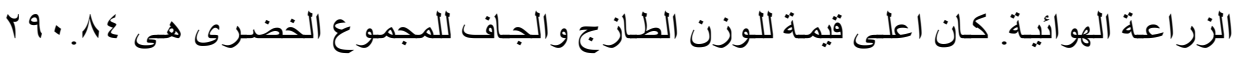

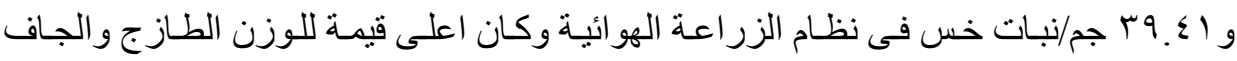

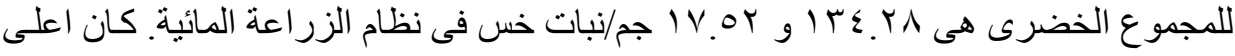

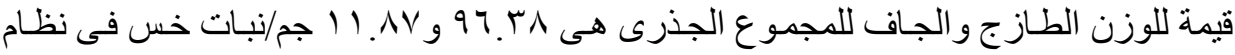

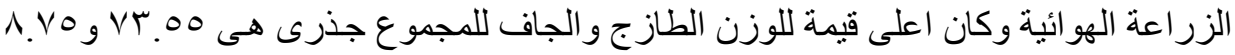

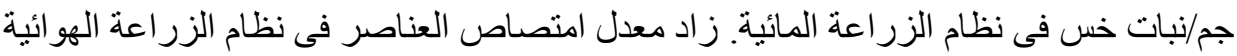

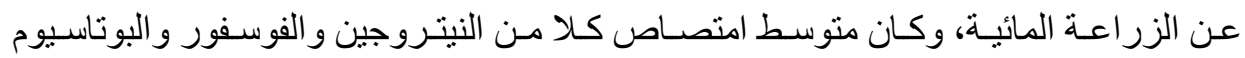

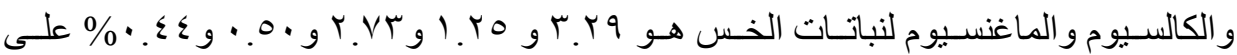

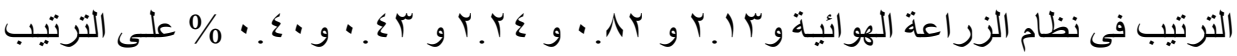

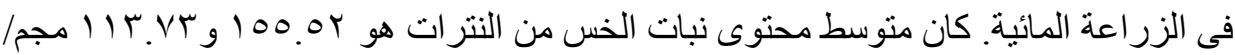

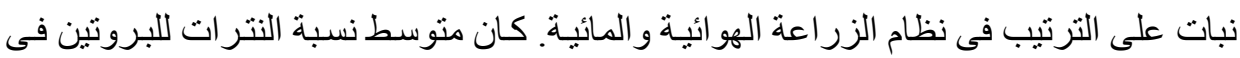

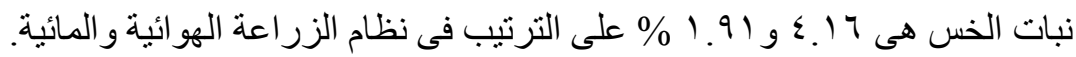

